\title{
A flexible upgrade path for the Australian National Broadband Network
}

\author{
Mark A. Gregory
}

RMIT University

\begin{abstract}
Summary. This paper provides a flexible upgrade path for the Australian National Broadband Network (NBN), if the new government decides to alter the construction methodology to include a copper-based access system such as Fibre to the Node (FTTN). The approach described in this paper utilises fibre past premises to provide a transmission media for a Gigabit-capable Passive Optical Network (GPON). GPON to FTTN devices would be situated in pits adjacent to premises and utilise copper tails to provide a VDSL2 Internet connection to premises. The approach provides a flexible upgrade path for customers to move from their copper based access system to a Fibre to the Home (FTTH) system utilising the relatively future-proof GPON.
\end{abstract}

\section{Introduction}

The Australian National Broadband Network (NBN) (Australian Government 2013) is a vital nation building project that has been plagued by ongoing criticism of the network design, cost blow-out claims and ongoing construction delays in its optical fibre rollout. Despite its grand ambitions, NBN Co has managed to connect far fewer premises to the NBN by optical fibre than originally identified in the first NBN Co rollout plan.

The Coalition Government took its NBN plan - promising a faster, cheaper rollout - to the federal polls in 2013 and, having won the election, has now acted quickly to reconstitute the NBN Co board and get the critical NBN-related reviews off the ground.

In the weeks prior to and immediately after the election, during visits to Cairns, Darwin and Geraldton, it became apparent to me that the NBN rollout is now in full swing around the nation. Being able to see what's happening on the ground outside capital cities provided a new perspective on the NBN and how it will affect our everyday lives.

During the site visits several NBN Co personnel and subcontractors mentioned that they were being asked the same question over and over again by people passing in the street: "Will the NBN get to my street (or suburb) before the election?"

Australians want the NBN, but how does the new government deliver on its promise to deliver the NBN faster, more affordably and sooner? 


\section{Design for upgrade and flexibility}

There have been suggestions made that future wireless or copper based technologies will make the need for an all optical NBN unnecessary. It's timely to remember that universities and industry research teams around the world test technologies that typically won't come to market for 15 to 20 years.

Unless there is a sudden and unexpected break-through in wireless or copper based technologies the only known approach to provide high speed broadband that incorporates traffic class management and Quality of Service (QoS) relies on the use of optic fibre.

\section{A smarter approach to FTTN}

So what are the possible engineering solutions available that will permit the government to achieve its pre-election plan and at the same time provide an optimal low-cost upgrade path to an all optical FTTH NBN?

To whittle down the possible engineering solutions it's necessary to introduce key design criteria for an optimal low-cost upgrade path from ADSL2+, FTTN, Fibre to the Basement (FTTB) and Hybrid Fibre Coax (HFC) to FTTH. (see Wikipedia 2013)

A list of the key design criteria highlights flexibility and upgradability as two build requirements that should take priority to ensure that there is an optimal low-cost upgrade path that's compatible with the existing NBN and flexibility for telcos, service providers and customers.

To achieve the two build requirements, utilising the key design criteria, the need for an engineering solution became apparent. And there is a way of making this happen.

\section{A new NBN design}

The current fibre rollout past premises should continue unabated because the fibre really needs to go as close as possible to premises, to meet foreseen future bandwidth needs(Ruthven 2012).

In the interests of facilitating a cheaper upgrade path, equipment vendors should be invited to supply devices that plug into the fibre multi-ports that provide ADSL2+/VDSL2/VDSL2 with vectoring. The ADSL2+/VDSL2/VDSL2 with vectoring customer premises modem or an additional plug pack located in premises would provide power over the copper cable to the xDSL device located in the street.

The xDSL device may include one or more ports where each port would be powered by an active connection. 
The current NBN design utilising GPON (see Wikipedia 2013) and a passive fibre design configuration should be retained. This means the ADSL2+/VDSL2/VDSL2 with vectoring devices that plug into the fibre multi-ports would need to convert the ADSL2+/VDSL2/VDSL2 signals with vectoring to GPON before they enter the fibre.

When G.Fast (Brown 2013) becomes available, equipment vendors would be encouraged to add G.Fast to the devices.

An alternative solution is to transfer the xDSL/G.Fast traffic up the fibre utilising a separate light wavelength to that used for the GPON network, but this is less elegant.

\section{Benefits of a flexible upgradable NBN design}

The engineering solution outlined above provides an upgrade path from ADSL2+ to VDSL2 to VDSL2 with vectoring to G.Fast and finally to GPON. The approach would utilise the installed copper pairs, but limit the length of the copper used to provide for optimal xDSL speeds depending on the state of the copper rather than attenuation due to the length.

What this means is that telcos, service providers and retail customers are provided with flexibility and a low cost approach to upgrade from one technology to the next (Gregory 2013).

Those end users who do not want to wait and want GPON immediately can either install the fibre into their premises themselves or pay a local contractor to do it for them. The cost of utilising a contractor would be about $\$ 1000$ to $\$ 1500$ based on figures from a recently leaked NBN Co document made available to Business Spectator (Kohler 2013), as compared to up to $\$ 3,000$ for opting for fibre from a local cabinet.

Some service providers are likely to offer plans that incorporate the cost of running fibre into premises, on longer term contracts. This would not be an unusual move as customers often pay for handsets to be included on mobile phone plans where some of the handsets cost upwards of $\$ 800$.

The implementation of NBN access to premises with poor copper transmission speeds may need to fall back from G.Fast or VDSL2 to ADSL2+ or ADSL2 and finally to ADSL in the worst case. However, it is better to have graceful degradation than to try to force VDSL2 with vectoring over defective copper. 


\section{Cabinets are not needed}

By adopting this engineering solution there would be no need to put 80 to 100,000 large cabinets on streets around the nation that would be filled with batteries and equipment needing large amounts of power drawn from the local supply (or from residents' household supplies).

There would also be no need to dig up streets to redirect copper from the existing pillar points to the cabinets. Carving up the streets becomes necessary because the copper tails from the pillar points are typically up to 750 metres in length whilst VDSL2 with vectoring is only practical over about 300-400 metres of copper, based on UK experience.

There would also be a need to run fibre down the street to the cabinet, so if the streets are to be dug up why not continue with the GPON fibre rollout past premises or into premises basements?

A key aspect of the design is there should be no need to re-negotiate with Telstra for the purchase or use of copper. The portion of the copper tails to be used resides primarily on premises and property owners are likely to be able to use the copper in any way they see fit if it is disconnected from the Telstra network.

\section{An overseas example}

Swisscom, a Swiss telecommunications provider, trialed Fibre to the Street (FTTS) technology in 2012 (Swisscom 2012). In 2013 Swisscom announced that it was proceeding with a FTTS rollout in areas that were not as densely populated as the major urban areas. The Swisscom FTTS rollout will utilise fibre cable to the street ducts about 200 metres from buildings and then utilise the existing copper into premises. The Swisscom approach removes the need for large cabinets to be placed on suburban streets but is utilising active network technologies rather than the passive optical network proposed for the Australian solution (Swisscom 2013).

Swisscom's Head of Technical Management, Amaury de Gromard, described the FTTS approach as follows: 
"In addition to FTTH, FTTS will be our next focus in the coming years and it is expected to help us replace our legacy FTTC infrastructure. With FTTS, we install the active equipment in manholes and move it extremely close to customers (less than 20om away). In this way, the fibre is about 200 metres close to the households, with the remainder connected through copper. Between the exchanges and manholes, the fibre feeders are ready for FTTH upgrade, when a customer demands higher bandwidth." (de Gromard 2013)

Power can be provided over copper from premises at $48 \mathrm{~V}$ for the active components located in ducts if a passive fibre rollout occurs for fibre past premises or for FTTS. The total power per port would be around $1 \mathrm{~W}$ so providing power does not require much innovation. Customer connections or groups of customer connections can be powered individually or collectively (Jackson 2013; PR Newswire 2012).

\section{Consider all options}

The simplest approach for industry, but not the best for the nation's end users, would be to duplicate the FTTN rollout carried out in the UK. Recently the Communications Alliance (Communications Alliance 2013a), which is the telecommunications industry body that facilitates industry-based solutions, commenced a working committee to look at the introduction of VDSL2 and Vectoring for the NBN (Communications Alliance 2013b). A review of the working committee documentation and guidelines identified that the working committee is focused on a UK style FTTN solution.

That solution requires the installation of street cabinets with power, batteries and equipment for decades to come. The problem is that the UK FTTN model is not compatible with a future GPON FTTP network and this means there would be a considerable cost to upgrade the entire nation from FTTN to FTTP.

It's important that the government give the telecommunications industry guidance and insist that the industry consider every option if FTTN is to be introduced into the NBN.

There are more than 10 million premises in Australia and this offers sufficient scale for equipment vendors to build devices that contain ADSL2+/VDSL2/VDSL2 with vectoring/G.Fast (in the future) and convert to GPON before connecting to a multi-port on a GPON fibre network.

The new government has an opportunity to redirect the NBN without stopping the existing fibre-passed premises rollout and thereby achieve goals put to voters before the last election. More importantly. it will be able to provide an upgrade path that is compatible with the existing NBN and flexibility for telcos, service providers and customers. 


\section{Conclusion}

The approach described in this paper provides a flexible upgrade pathway for the NBN that utilises fibre past premises and copper based access technologies into premises. A benefit of the approach is the flexibility provided to customers who can opt at their own relatively small cost to have fibre run into their property and thereby upgrade their property to be compatible with the estimated $22 \%$ of the Australian FTTP NBN which will utilise GPON under the new Government's plan. The cost of the approach to government would be more expensive than the UK FTTN model of fibre to the cabinet in the short term but would significantly lower the cost of completing a national FTTP upgrade in the medium term.

\section{References}

Australian Government 2013. "National Broadband Network', Australian Government. Accessed online 1 October 2013 at http://www.nbn.gov.au/

Brown, T. 2013. "G.Fast's place in a full fibre world", Technology Spectator, o9 August 2013. Accessed online 1 October 2013 at http://www.businessspectator.com.au/article/2013/8/9/technology/gfasts-place-fullfibre-world

Communications Alliance. 2013a.Communications Alliance Ltd. Accessed online 1 October 2013 at http://www.commsalliance.com.au/

Communications Alliance. 2013b. "Industry Moves to Assist Introduction of VDSL2 and Vectoring for the NBN", Communications Alliance Ltd, 23 September 2013. Accessed online 1 October 2013 at http://www.commsalliance.com.au/about-us/newsroom/201315

de Gromard, A. 2013. "Swisscom: Boosting the fiber roadmap with innovative technologies", Swisscom, 2013. Accessed online 1 October 2013 at

http://www.huawei.com/ilink/en/solutions/broader-smarter/morematerialb/HW_260629

Gregory, M.A. 2013. "Will the NBN be 'affordable' without Huawei?", Technology Spectator, 2 October 2013. Accessed online 5 October at http://spectatoro1.businessspectator.com.au/article/2013/10/2/technology/will-nbn-beaffordable-without-huawei

Jackson, M. 2013. "UPD Alcatel-Lucent on G.Fast and Vectoring 2 for Future 1Gbps FTTC Broadband", ISPreview, 9 July 2013. Accessed online 1 October 2013 at http://www.ispreview.co.uk/index.php/2013/o7/alcatel-lucent-talk-g-fast-andvectoring-2-for-future-1gbps-fttc-broadband.html

Kohler, A. 2013. "The NBN is now Malcolm’s Mess", Business Spectator, 25 September 2013. Accessed online 5 October 2013 at http://www.businessspectator.com.au/article/2013/9/25/information-technology/nbnnow-malcolms-mess 
PR Newswire. 2012."Lantiq Breaks 100 Mbps Barrier for Reverse Powered Fiber to the Distribution Point (FTTdp) Solution", PR Newswire, 10 October 2012, Accessed online 1 October 2013 at http://www.prnewswire.com/news-releases/lantiq-breaks-100-mbpsbarrier-for-reverse-powered-fiber-to-the-distribution-point-fttdp-solution173440191.html

Ruthven, P. 2012. "A Snapshot of Australia's Digital Future to 2050", IbisWorld Report, June 2012, accessed online 1 October 2013 at http://www07.ibm.com/au/pdf/1206_AustDigitalFuture_A4_FINALonline.pdf

Swisscom. 2012. "Ultra-fast Internet in Grandfontaine: Swisscom testing new fibre-optic technology", Swisscom, 21 November 2012. Accessed online 1 October 2013 at http://www.swisscom.ch/en/ghq/media/mediareleases/2012/11/20121121_MM_Glasfas er_Grandfontaine.html

Swisscom. 2013. "Swisscom chooses Huawei as supplier for its FTTS expansion", Swisscom, 12 February 2013, Accessed online 1 October 2013 at http://www.swisscom.ch/en/ghq/media/mediareleases/2013/02/20130212_MM_Huaw ei_FTTS_Ausbau.html

Wikipedia. 2013. "Fiber to the X", Wikipedia, Accessed online 1 October 2013 at http://en.wikipedia.org/wiki/Fiber_to_the_x

Cite this article as: Gregory, Mark A. 2013. 'A flexible upgrade path for the Australian National Broadband Network'. Australian Journal of Telecommunications and the Digital Economy 1 (1): pp.17.1 - 17.7. DOI: 10.7790/ajtde.v1n1.17 Available at: http://telsoc.org/journal 